\title{
A ECOLOGIA DOS MEIOS E A TECNOLOGIA COMO IMERSÃO CULTURAL
}

\author{
MEDIA ECOLOGY AND TECHNOLOGY AS CULTURAL IMMERSION \\ LA ECOLOGÍA DE LOS MEDIOS Y LA TECNOLOGÍA COMO IMERSIÓN CULTURAL
}

Magda Pischetola ${ }^{1}$

Liliane Balonecker Daluz ${ }^{2}$

\begin{abstract}
${ }^{1}$ Doutora em Educação pela UCSC. Docente do Programa de Pós-Graduação em Educação da Pontifícia Universidade Católica do Rio de Janeiro (PUC/RIO), Rio de Janeiro, RJ, Brasil.
\end{abstract}

${ }^{2}$ Doutoranda em Educação pela Pontifícia Universidade Católica do Rio de Janeiro (PUC/RIO), Rio de Janeiro, RJ, Brasil.

Resumo: A perspectiva teórica da ecologia dos meios, abordada por McLuhan (1962), Postman (1970) e Ong (1982), compreende as mídias como ambientes culturais imersivos, em que os aspectos relacionais ganham relevância. Migrando o foco dos efeitos das mídias para as linguagens que as constituem, a ecologia dos meios busca compreender as mudanças significativas que as tecnologias trazem nas esferas comunicativas, políticas, econômicas e sociais. O objetivo deste artigo é investigar a integração de tecnologias no ambiente escolar sob a perspectiva da ecologia dos meios, apresentando uma pesquisa desenvolvida entre 2014 e 2016 em oito escolas municipais da cidade do Rio de Janeiro. O estudo, de cunho qualitativo, envolveu 80 sujeitos de pesquisa, entre professores, diretores e coordenadores pedagógicos. Os resultados apontam para a presença da tecnologia na escola em sua vertente cultural e, ao mesmo tempo, para vicissitudes que envolvem o reconhecimento e a dificuldade em lidar com essa presença.

Palavras-chave: Ecologia; Meios de Comunicação; Cultura da Escola; Tecnologia.

\begin{abstract}
The theoretical perspective of media ecology, addressed by McLuhan (1962), Postman (1970) and Ong (1982), views the media as immersive cultural environments in which relational aspects gain relevance. Shifting the focus from the effects of the media to the languages that constitute them, media ecology seeks to understand the significant changes that technologies have brought in the communicative, political, economic and social spheres. The aim of this article is to investigate the integration of technologies in the school environment from the perspective of media ecology. It presents a study carried out between 2014 and 2016, in eight municipal schools in the city of Rio de Janeiro. The qualitative study involved eighty research subjects, including teachers, school Principals and pedagogical coordinators. The results show the presence of technology in the school from a cultural point of view and the vicissitudes that make it difficult for the school actors to recognize and deal with this presence.
\end{abstract}

Keywords: Ecology; Communication research; Educational environment; Technology.

Resumen: La perspectiva teórica de la ecología de los medios, abordada por McLuhan (1962), Postman (1970) y Ong (1982), comprende los medios como entornos culturales inmersivos, en los que los aspectos relacionales ganan relevancia. La ecología de los medios busca comprender los cambios significativos que las tecnologías traen en las esferas comunicativas, políticas, económicas y sociales. 
El objetivo de este artículo es investigar la integración de tecnologías en el ambiente escolar desde la perspectiva de la ecología de los medios, presentando una investigación desarrollada entre 2014 y 2016 en ocho escuelas municipales de la ciudad de Río de Janeiro. El estudio, de cuño cualitativo, involucró a 80 sujetos de investigación, entre profesores, directores y coordinadores pedagógicos. Los resultados indican que la tecnología está presente en la escuela en su vertiente cultural y, al mismo tiempo, muestran que hay eventos contextuales que dificultan a los actores escolares el reconocimiento y administración de esa presencia.

Palabras clave: Ecología; Medios de Comunicación; Cultura de la Escuela; Tecnología.

\section{A Ecologia dos Meios: Marshall Mcluhan, Neil Postman e Walter Ong}

Na tentativa de refletir sobre as transformações que se fazem prementes em nosso atual cenário social, marcado por um forte teor tecnológico, recorremos à verve metafórica de Marshall McLuhan (1962; 1964) e sua perspectiva de interpretação da realidade sob a lente de uma ecologia dos meios. O conceito foi cunhado por McLuhan, mas oficialmente apresentado ao público no ano de 1968 por Neil Postman, que o definiu como o "estudo dos meios como ambientes" (1970, p. 161)

Tanto McLuhan (1962; 1964) quanto seus seguidores mais próximos, Neil Postman (1970; 1998; 2000) e Walter Ong (1982; 2002), recorrem a figuras de linguagem para tentar explicar seus pensamentos: metáforas e comparações entram no jogo de significações. McLuhan exprime suas ideias por meio de aforismos que marcam o seu discurso polêmico e futurista. Sua frase "o meio é a mensagem" propaga-se no âmbito acadêmico e secular e gera muitas controvérsias. Com essa afirmação, o autor entende que os meios, as tecnologias, são mensagens em si, por sua própria existência na sociedade. O fundamental não é, portanto, o conteúdo veiculado por um meio, mas o próprio meio em si, pois este, além de sua materialidade técnica é, acima de tudo, ambiente cultural.

Vistos sob essa perspectiva, os meios configuram-se também como extensões do homem. Compreendê-los dessa forma significa que, longe de serem concebidos apenas como instrumentos ou ferramentas das quais o homem se serve, os meios são uma espécie de prolongamento do ser humano, de seu corpo e sua forma de pensar, ou seja, constituem-se como maneiras de traduzir um modo de conhecer o mundo. Nas palavras de McLuhan (1964):

Qualquer invenção ou tecnologia é uma extensão ou auto-amputação de nosso corpo, e essa extensão exige novas relações e equilíbrios entre os demais órgãos e extensões do corpo. Assim, não há meio de recusarmo-nos a ceder às novas relações sensoriais ou ao "fechamento" de sentidos provocado pela imagem da televisão. Mas o efeito do ingresso da imagem da televisão variará de cultura a cultura, dependente das relações sensoriais existentes em cada cultura. (MCLUHAN, 1964, p. 63).

Na visão do autor, o uso de qualquer meio modifica os sentidos, como resultado da extensão do sistema físico e nervoso. As extensões não são "nem sucedâneos tecnológicos, nem agregações mecânicas, mas efeitos de sentido" (MACHADO, 2009, p. 22), o que equivale a 
dizer que a dimensão dessas extensões é preponderantemente cultural, pois se trata de uma (re)organização simbólica do homem.

McLuhan afirma que os seres humanos modelam os artefatos midiáticos ao mesmo tempo em que são modelados por estes, em um processo totalmente marcado pela interação. O tema é posteriormente retomado pelo escritor David Wallace que, em 2005, ilustra a ideia utilizando-se de uma alegoria, trazendo o exemplo do peixe que se move imerso na água, sem se dar conta da existência do mar². Conforme Logan (2011), afirmar que o meio é a mensagem significa dizer que, independente de seu conteúdo, as mídias têm seus próprios efeitos intrínsecos sobre nossa percepção e relação com o mundo. O próprio McLuhan, em uma entrevista, quando interpelado a explicar seu aforismo, esclarece:

Quando afirmo que o meio, o meio de difusão, é a mensagem, isso diz respeito ao efeito desse meio na sociedade como um todo, à maneira como ele transforma todo mundo. Isso é a mensagem, e não seus efeitos particulares. (MCLUHAN, 2011, p. 3).

Dessa forma, entendemos que cada tecnologia tende a criar um novo ambiente humano, modificando sobremaneira a cultura do seu tempo. Toda tecnologia cria novas tensões e necessidades nos seres humanos que a engendraram, transformando o entorno por meio de dinâmicas de interação e interdependência. Trata-se, portanto, de uma perspectiva segundo a qual as mídias e as tecnologias são vistas de forma indissociável dos processos de socialização, sendo pensadas "no contexto da ecologia dos sentidos, que desencadeia relações, conexões, associações entre diferentes esferas". (MACHADO, 2009, p. 20).

Se a abordagem de McLuhan foca principalmente na praxe, nas ações e nas atividades que a relação homem-mídia impulsiona, a ênfase de Neil Postman na ecologia dos meios é posta na possibilidade de utilizar essa conceituação como campo/método de investigação, sobretudo para a área pedagógica. Segundo Postman (1970; 1998; 2000), a mudança tecnológica não é apenas aditiva, cumulativa, mas marcada por uma relação dialógica entre os objetos e os sujeitos que definem uma época histórica. Exemplifica, então, da seguinte maneira: ao deixarmos cair uma gota de corante vermelho em um recipiente com água, acontece de todo o líquido ficar avermelhado, ou seja, a tinta se dissolve e se mistura à água, colorindo cada uma das moléculas. Nessa perspectiva, Postman concebe a mudança ecológica dos meios de comunicação como o surgimento de um novo meio, de uma nova mídia, que não se limita a agregar elementos ao sistema existente, mas, sobretudo, exerce modificações no todo, causando impacto em todo o ambiente, de forma ampla.

O autor afirma que a utilização do termo "ecologia" sugere que não interessa estudar somente os meios, isoladamente, mas sim as formas com que a interação entre os seres humanos e os meios molda o caráter da cultura, ajudando a compreendê-la. Segundo Scolari (2010), a consolidação de uma visão ecológica dos meios foi concomitante à propagação das ideias de ecologistas a partir da década de 1960. No entanto, observa Postman, essa perspectiva existe desde tempos remotos, definida e abordada com diferentes nomenclaturas, tendo como centro a interação homem-meios como um elemento que pode aumentar ou diminuir as possibilidades de sobrevivência (STRATE, 2004). Segundo ele, cada tecnologia carrega consigo uma filosofia que expressa o modo com que as pessoas usam suas mentes, 
seus corpos, como codificam o mundo. A mudança tecnológica é uma mudança "ecológica", ou seja, uma mudança "total".

Uma mudança significativa gera uma mudança total. Se você tirar as lagartas de dado habitat,
você não fica com o mesmo ambiente menos as lagartas, mas com um novo ambiente e terá
reconstruído as condições da sobrevivência; o mesmo se dá se você acrescenta lagartas a
um ambiente que não tinha nenhuma. É assim que a ecologia do meio ambiente funciona.
Uma tecnologia nova não acrescenta nem subtrai coisa alguma. Ela muda tudo. No ano
de 1500, cinquenta anos depois da invenção da prensa tipográfica, nós não tínhamos a
velha Europa mais a imprensa. Tínhamos uma Europa diferente. (POSTMAN, 1994, p. 27).

De acordo com essa concepção, a ecologia dos meios analisa como os meios de comunicação afetam a percepção, a compreensão, as sensações, os valores presentes em uma dada realidade. Ressalta ainda que o termo "ecologia" implica o estudo de ambientes, sua estrutura, o conteúdo e o impacto sobre as pessoas, e que um ambiente configura um sistema de mensagens, implícitas e explícitas, que impõe formas de pensar, sentir e agir. Segundo o autor, "um meio é uma tecnologia em que uma cultura cresce; ou seja, ele dá forma à política, organização social e modos de pensar de uma cultura." (POSTMAN, 2000, p. 10)3.

Seguindo o caminho indicado por McLuhan, seu aluno Walter Ong (1982; 2002) estuda a comunicação oral e escrita, as características de cada modelo e seus impactos na cognição humana. Em sua obra mais conhecida, Oralidade e cultura escrita, publicada originalmente em 1982, Ong apresenta o pensamento e a expressão de ambas as modalidades da língua, analisando suas diferenças como recursos comunicativos. Segundo o autor, a aquisição da escrita tem um impacto sensorial e cognitivo, transformando não somente a palavra e o seu uso, mas também os modos de pensamento. Os reflexos dessa transformação em toda a sociedade são ampliados ainda mais com a palavra impressa, apontando para uma evolução das capacidades analíticas e interpretativas dos leitores. Embora o seu foco esteja claramente no contraste entre culturas orais e alfabetizadas, Ong também discute a universalidade da fala, a distinção entre o alfabeto e outros sistemas de escrita e a relação entre oralidade e os meios eletrônicos (STRATE, 2004).

A partir dessas reflexões, Ong (2002) refere-se à ecologia dos meios como a perspectiva teórica que apresenta um interesse pelo ambiente, quase um novo estado da consciência, que poderia ecoar as inquietudes que impulsionaram Charles Darwin para a definição do sistema de evolução humana. Tal seria o aporte da ecologia dos meios para o estudo e a compreensão da cultura como o ambiente em que os símbolos humanos e suas relações são criados e evoluem.

Nosso fascínio atual com a ecologia, percebida em todas as suas formas, depende da explosão de informação que marca a nossa época e que nos tornou mais conscientes das correlações entre todos os seres vivos e as estruturas do universo ao nosso redor. Aumentando o nosso conhecimento da evolução cósmica e orgânica e das relações que constituem essa evolução, focamo-nos, em última análise, na vida humana. (ONG, 2002, p. 6).

Segundo a definição de Ong (2002), a perspectiva da ecologia dos meios seria um "sistema aberto", capaz de incentivar a criatividade, a liberdade e o processo de descoberta, embora seja preciso destacar a complexidade que consiste em mapear o próprio sistema. Muito mais do que uma metáfora emprestada da área biológica aplicada ao estudo das mídias, a ecologia dos meios constitui uma base teórico-epistemológica fecunda no campo de investigação das 
novas tecnologias, trazendo em seu âmago o pressuposto de que os meios, na condição de espécies que coexistem em um ecossistema por meio de relações e interações, constituem um entorno, uma ambiência, as quais promovem significativas modificações na sociedade.

\section{TECNOLOGIAS E APROPRIAÇÃO CULTURAL}

Em consonância com os pensamentos difundidos pela perspectiva teórica da ecologia dos meios, compreende-se a tecnologia como cultura e, como tal, constituidora de ambientes, em constante processo de evolução e modificação. Ao mesmo tempo em que o homem transforma a tecnologia, por ela também é constantemente transformado. Essa visão ecológica e cultural dos meios - fundada em conceitos de vida, sobrevivência, interação - supera, portanto, os tradicionais enfoques mecanicistas - baseados em conceitos como controle, utilitarismo, eficiência e poder (PISCHETOLA, 2016; SCOLARI, 2010). Enfatiza-se, desse modo, que os meios só adquirem sentido em relação com outros meios, como espécies que convivem em um mesmo ecossistema de comunicação, em relação de interdependência. Nesse sentido, a pesquisa em torno das tecnologias e das mídias é concebida, sobretudo, a partir de um enfoque cultural.

Como destacam Carvalho e Barichello (2013), a ecologia dos meios se constituiu como uma perspectiva mais complexa e integradora sobre o estudo dos meios, difundindo a ideia de que os meios fundam ambientes culturais, alegando que nenhum meio existe ou tem sentido sozinho, mas em relação com outros. Esse caráter relacional dos meios destaca que a mudança é um

processo, sobretudo, cultural, não apenas técnico, pois cada mudança no ambiente afeta os meios, assim como cada novo meio que emerge afeta a totalidade do ecossistema cultural.

Nesse sentido, conforme destaca Scolari (2008; 2010; 2012), torna-se crucial que as pesquisas ultrapassem a mera descrição e comecem a desenvolver estratégias teóricometodológicas que se aprofundem no estudo sobre as mídias em interlocução com a ecologia dos meios. Assim, o autor enfatiza a importância da ecologia dos meios no cenário atual das pesquisas sobre as mídias e tecnologias digitais:

En un entorno marcado por la consolidación de las redes globales de información, los procesos
de convergencia y la explosión de nuevos medios y plataformas de comunicación, la aparición
de narrativas transmediáticas y la irrupción de un paradigma de la comunicación muchos-a-
muchos que rompe el modelo tradicional del broadcasting, las reflexiones de la ecologia de los
medios se presentan como una referencia casi indispensable a la hora de comprender estos
procesos. La ecologia de los medios propone temas, conceptos y preguntas que enriquecen
las conversaciones científicas sobre la comunicación digital interactiva. (SCOLARI, 2010, p. 24).

Em um contexto em que se proliferam, a cada dia, novas espécies midiáticas, destacase, por conseguinte, a necessidade de se olhar além dos elementos técnicos e seus efeitos, analisando-se múltiplas dimensões interligadas e interativas de poder, resistências, tempos e espaços, sociabilidades, linguagens e símbolos presentes nos atuais sistemas digitais (RUBLESCKI; BARICHELLO, 2013). Conforme salienta McLuhan (1964), nenhum meio existe sozinho ou tem um significado isolado, mas sim em permanente relação com outros meios.

Assim sendo, faz-se necessário lançar um olhar mais atento às interações, não apenas aos aparatos técnicos, como se estes existissem isoladamente, como fins em si mesmos. Também 
não podemos perder de vista o fato de que a tecnologia não é neutra e, nessa medida, sua adoção está intrinsecamente marcada por tensões que questionam, alteram e reinventam seu uso. Nesse sentido, em cada tecnologia reside um viés específico, que impulsiona um movimento necessário de "apropriação cultural do meio tecnológico, incluindo o exercício de autoria e o acesso às diferentes formas de produção de conhecimento." (PISCHETOLA, 2016, p. 87). Ademais, a ubiquidade das tecnologias digitais da informação e da comunicação demandaria, mais do que acesso e capacitação técnica, uma verdadeira imersão nesse universo digital, marcado por novos modos de ser e estar no mundo, novos letramentos e processos de autoria, assim como novos modos de pensamento, conforme sugere a perspectiva da ecologia dos meios (BUZATO, 2010; MALHEIROS, 2017; NAUMANN; PISCHETOLA, 2017).

Defendemos, portanto, neste trabalho, que a escola é peça fundamental no processo de reflexão e apropriação das tecnologias (DALUZ, 2014). A escola como lugar de discernimento, cujas pessoas possam adquirir o direito de refletir e interpretar o dito e o não dito, as linhas e as entrelinhas da existência. As tecnologias digitais favorecem a mobilização, o estabelecimento de uma cultura de participação, que incentiva a criação, a expressão e o engajamento político dos atores envolvidos e imersos nessa cultura. No entanto, diante da grande quantidade de informação e dados disponíveis, faz-se necessária uma educação voltada para o desenvolvimento de uma apropriação crítica e criativa, que forme indivíduos que não sejam apenas consumidores passivos de objetos sócio-técnicos, mas cientes de que vivenciam uma contemporaneidade que é uma construção histórica, social e cultural, marcada pela dialética entre o velho e o novo, por meio de um processo contínuo de reorganização das relações sociais mediadas pelas tecnologias.

Com foco nas práticas docentes, conforme destaca Malheiros (2017), a pesquisa compreende que a apropriação de tecnologias digitais é um processo em constante movimento, que envolve não somente a assimilação dos componentes técnicos de seu uso, mas também a ampliação das perspectivas de análise, a negociação de critérios convincentes para o seu uso na escola, a compreensão de suas finalidades de aplicação e o desenvolvimento de novas habilidades, na direção dos multiletramentos (NAUMANN; PISCHETOLA, 2017). Logo,

defendemos que a apropriação de tecnologias na escola implica um processo de imersão cultural de todos os atores envolvidos.

\section{TECNOLOGIAS NA ESCOLA: UMA IMERSÃO CULTURAL?}

A introdução das tecnologias nos contextos escolares avança para a discussão sobre a produção de conhecimento, para a demanda por estratégias didáticas que promovam a centralidade do aluno e a aprendizagem por descoberta. Porém, pesquisas da última década apontam para a dificuldade dos professores em introduzir as tecnologias em sua prática pedagógica de forma inovadora, devido a uma atitude de insegurança e à necessidade de revisão das linguagens utilizadas (PISCHETOLA, 2016).

Esses elementos apontam para a necessidade de se encarar a tecnologia em sala de aula não apenas como ferramenta, mas como cultura e, para tanto, é fundamental que adotemos 
uma perspectiva que compreenda as mudanças socioculturais advindas da cultura digital (HEINSFELD; PISCHETOLA, 2017; LÉVY, 1993; LEMOS, 2009). À medida que a tecnologia permite a colaboração entre os alunos, debates para uma melhor compreensão dos temas, crítica aos conteúdos apresentados durante a aula e o incentivo das produções de argumentos por parte do aluno que justifiquem seu posicionamento, ela pode ser considerada um artefato cultural. Nessa perspectiva, o desafio cultural para o professor é estabelecer sua própria metodologia de uso das tecnologias em sala de aula, não apenas reproduzindo práticas pedagógicas tradicionais, mas explorando novos caminhos metodológicos.

Nos termos delineados pela pedagogia sócio-histórica (VYGOTSKY, 1991; 2009), a mediação pedagógica em contexto de cultura digital acontece somente quando o professor oferece a oportunidade de acesso dos alunos às mídias, explorando suas possibilidades de desenvolvimento potencial. Dessa forma, o papel do professor é provocar no aluno o interesse por aprender com as mídias, gerando debates em torno de temas levantados por estas mesmas mídias, relacionando esses temas com as experiências dos alunos, favorecendo a reflexão crítica, o diálogo e a interação.

\section{RELATO DA PESQUiSA REALIZADA EM OITO ESCOLAS MUNICIPAIS DO RIO DE JANEIRO}

A pesquisa apresentada a seguir teve como objetivo a análise das estratégias de integração cultural das tecnologias digitais em contexto escolar, a partir da concepção e da prática de professores e gestores das escolas pesquisadas. A investigação, de abordagem qualitativa, foi realizada em oito escolas públicas municipais de Ensino Fundamental da cidade do Rio de Janeiro, no período entre outubro de 2014 e dezembro de 2016.

A opção metodológica por uma abordagem qualitativa justifica-se com base nos dois objetivos da investigação: (1) conhecer e analisar as estratégias pedagógicas de uso de tecnologias em sala de aula; (2) conhecer e analisar as visões e as percepções dos professores sobre o uso pedagógico de tecnologias. Em particular, no âmbito desse segundo objetivo de pesquisa, é interessante entendermos e avaliarmos a visão dos professores com respeito aos usos que os alunos fazem dessas ferramentas e seu entendimento com respeito à tecnologia como parte fundante da cultura contemporânea.

Para a composição do campo da pesquisa, selecionamos escolas de segundo segmento do Ensino Fundamental II situadas em áreas da cidade com diferentes contextos socioculturais - Oswaldo Cruz, Méier, Jacarepaguá, Centro, Bangu, Vila Militar, Humaitá, Vila Isabel - em número que possibilitasse uma comparação e uma possível generalização dos resultados. Cabe salientarmos que as escolas foram indicadas pela própria Secretaria Municipal de Educação do Rio de Janeiro, pela relevância apresentada por elas no âmbito de projetos que envolvessem diferentes tipos de mídias e tecnologias, o seu uso interdisciplinar e o aspecto da continuidade temporal do projeto, em acordo com os objetivos da pesquisa de investigar os elementos das boas práticas pedagógicas e a sustentabilidade cultural e econômica dessas iniciativas (PISCHETOLA, 2015; 2016). 
Foram utilizados dois instrumentos de pesquisa: (1) entrevistas semiestruturadas com professores e gestores (diretores e coordenadores), desenvolvidas a partir de um roteiro de perguntas previamente elaborado, mas cuja sequência era flexível, adaptando-se ao contexto da conversa entre pesquisador e participantes; (2) observação participante em sala de aula, com foco nas práticas pedagógicas com uso de tecnologias, fundamentada em uma planilha de indicadores iniciais a serem observados (entre eles, as atividades propostas pelo professor, a relação professor-aluno em sala de aula, o envolvimento e a motivação dos alunos, os indicadores de colaboração e ajuda mútua). No período de desenvolvimento da pesquisa, foram realizadas um total de 80 entrevistas - com 8 professores e 2 gestores em cada uma das escolas - e 384 horas de observação em sala de aula - 2 professores em cada escola, por um período de 12 semanas.

\section{RESULTADOS PRINCIPAIS}

Adotamos como referência para a construção da metodologia de análise de dados a Teoria Fundamentada em Dados (Grounded Theory), criada por Glaser e Strauss em 1967 e composta por quatro etapas: coleta dos dados empíricos; procedimentos de codificação ou análise dos dados; codificação aberta, codificação axial ou formação e desenvolvimento do conceito; codificação seletiva ou modificação e integração do conceito e delimitação da teoria. A metodologia, extremamente eficaz, mas pouco utilizada nos estudos nacionais, baseia-se nos dados produzidos no campo, com o objetivo de gerar explicações para ações dos indivíduos dentro de um contexto social de estudo (CASSIANI, CALIRI \& PELÁ, 1996).

A análise dos dados foi realizada na tentativa de encontrar padrões que mais se enquadrassem no conceito de cultura, até os que mais se distanciassem dele, a partir de um continuum imaginário, que poderia ser representado, visualmente, como se segue:

Figura 1 - Percepções dos professores em relação às tecnologias.

PERSPECTIVA

TECNICISTA

Inevitável (12 profs.)

$\rightarrow$ Precisa se adaptar
Motivadora (18 profs.)

Facilitadora (17 profs.)
Inevitável (15 profs.)

$\rightarrow$ Precisa mediar
PERSPECTIVA

RELACIONAL

Imersiva (2 profs.)

Fonte: Os autores, pesquisa de campo.

A partir dos dados coletados, observamos que, de modo geral, as instituições pesquisadas demonstram alguma preocupação com a inclusão de tecnologias, disponibilizando recursos e programações que buscam a acessibilidade. Entretanto, a perspectiva cultural não é priorizada. A maioria dos entrevistados reconheceu a importância das tecnologias para a inovação da 
escola no momento histórico atual. Ao mesmo tempo, contudo, o relato das práticas didáticas e a observação em sala de aula revelaram a dificuldade de aplicar essas convicções ao trabalho pedagógico cotidiano.

Com a análise das entrevistas, tendo como base os conceitos apresentados, percebemos que, dentre os 64 professores entrevistados: 27 professores declararam que as tecnologias correspondem a "algo que não se pode mais evitar"; 18 professores se referiram às mídias dentro da escola como "um elemento de motivação para os alunos"; 17 professores consideraram as tecnologias como "um facilitador, um apoio para o professor" e somente 2 professores descreveram as tecnologias como "um ambiente no qual estamos imersos". Segue uma breve descrição de cada uma das categorias apontadas.

\section{A) - A tecnologia como algo inevitável}

Grande parte dos docentes entrevistados (27) relatou que a tecnologia digital é elemento de mudança inexorável e decisivo para a sociedade contemporânea e, portanto, a escola também precisa mudar. Foi possível identificar duas abordagens diferentes e polarizadas, uma que definimos como mais pessimista e outra como mais otimista. Na primeira categoria, foram identificadas 12 falas que pontuaram diferenças na atual geração, sugerindo que os alunos são capazes de utilizar as tecnologias com facilidade, "sabem muito", "são quase autodidatas" e que os professores, ao contrário, apresentam resistência à mudança e demonstram dificuldade em se adaptar. Seguem os depoimentos de dois professores que responderam à pergunta: "Qual a relação entre mídia e escola?":

Eu vejo que é uma relação extremamente importante, porque as gerações que vêm agora
dos alunos, já estão inseridas. Eu costumo até brincar com eles, dizendo que eles estão
nascendo com chip. Então, já nascem inseridos nisso, já mexem com as tecnologias e
com as mídias de maneira geral, eles já mexem com muita fluência. Sem nenhum curso
de capacitação, sem nenhuma necessidade de trabalhar isso neles. Eles sozinhos vão
aprendendo. Um vai dando dica pro outro, e vão trocando, mexendo e vão aprendendo. E a
gente acaba tendo um pouco de resistência a isso. (Professor de Matemática, escola 08). ${ }^{4}$
É uma relação, atualmente, necessária. Não é nem uma coisa eletiva,
que a gente pode escolher, porque ela invade de certa forma o
cotidiano da gente. (Professora de Língua portuguesa, escola 01).

Evidenciamos nas falas apresentadas um sentido de defasagem. Os professores relatam que percebem que suas práticas pedagógicas tradicionais são consideradas cada vez mais inadequadas e obsoletas, mas, ao mesmo tempo, não sabem de que forma modernizá-las. É interessante notar que muitos dos professores entrevistados não se sentem responsabilizados pela mediação pedagógica entre os alunos e as mídias. Por exemplo, não se responsabilizam por ensinar aos jovens a fazer seleção de conteúdo e utilizar a Internet, atribuindo apenas à família a incumbência de tal tarefa.

Os outros 15 professores alocados nessa primeira categoria de análise referente, ao que convencionamos chamar de "discurso da inevitabilidade", reconhecem que a mudança está acontecendo, mas propõem que, justamente por isso, a escola reconheça sua responsabilidade em mediar os usos de tecnologias, na perspectiva de ensinar ao aluno o melhor uso dessas 
ferramentas. Esses professores alegam que os alunos não sabem fazer "uso adequado" ou "uso correto" dos instrumentos de busca e conteúdo proporcionados pelas tecnologias. Segue um exemplo de fala na qual é possível perceber tal concepção:

Não dá para ignorar, só não dá para fazer uma aula $100 \%$ virtual, mas em algum
momento você pode trazer esse virtual a seu favor, até porque daqui para frente eu
acredito que o professor não será excluído - eu tenho colegas que dizem assim: "Ah, nós
seremos substituídos". Nós não seremos substituídos, porque mesmo com a Internet
é necessário que haja um mediador, porque a criança é bombardeada, e ela deixa
passar coisas despercebidas, como também nós deixamos. É porque é muito rápido, e
essa rapidez, alguma coisa a gente pode pegar. (Professora da sala de leitura, escola 04).

Os resultados da pesquisa mostram que também a maioria dos gestores escolares entrevistados apresenta a concepção de que ensinar o "uso correto" da tecnologia seria a única forma de promover, de fato, um esforço cognitivo que contribui para o aprendizado. Entre os entrevistados, é frequente o pensamento de que as tecnologias deveriam ser utilizadas como "aliadas" da educação. Porém, reconhecemos que essa afirmação considera as tecnologias como fundamentalmente neutras e somente o seu uso é o que diferencia o efeito a se obter. A partir dessas afirmações, surgem os questionamentos: existe um "uso correto" da mídia? Que outras formas de uso e apropriações são exiladas do bojo do conjunto que compõem o "uso correto" da mídia? Que outros modos de aprender e interagir com o conhecimento são ignorados em todas as suas potencialidades?

\section{B) - A tecnologia como um elemento motivador para o ALUNO/ FACILITADOR PARA O PROFESSOR}

Um grande número de professores se referiu à tecnologia como "recurso de animação" ou "incentivo" para o aluno (18), ou como atributo "facilitador" para o professor, no que tange ao ensino (17). Apesar de essas abordagens apresentarem, às vezes, algumas ideias interessantes de trabalho pedagógico, percebemos que se referem a uma visão ainda muito tecnicista, que encara a mídia como mero suporte didático e adicional e não como elemento cultural. Ou seja, acreditamos que somente por sua presença no espaço escolar as tecnologias provocariam motivação nos alunos ou seriam capazes de auxiliar o professor.

A gente trabalha com um público hoje que tem muito pouco interesse no ensino. E a mídia hoje, ela ajuda a focar em alguma coisa. Não quis dizer que efetivamente melhora na sua aprendizagem, mas é um atrativo para eles começarem a caminhar. (Professor de Matemática, escola 08).

Nas observações realizadas em sala de aula ficou claro que, muitas vezes, os professores que consideraram as tecnologias como suporte técnico eadicional não mudavam sua prática pedagógica tradicional. Por exemplo, em vez de utilizarem o quadro negro, simplesmente projetavam suas apresentações expositivas em PowerPoint, não obtendo, assim, maior participação e/ou interesse por parte dos alunos. Ao contrário, muitas vezes o entusiasmo do aluno pela expectativa de uma aula atrativa pela presença de tecnologias era frustrado frente a aulas pouco interativas. Com base nos resultados obtidos, percebemos que a visão da tecnologia como elemento motivador/ facilitador na sala de aula pode configurar a outra face da moeda da insegurança do professor 
frente às mudanças do mundo atual e à inadequação de práticas pedagógicas, em competição constante com as tecnologias, aclamadas como mais "chamativas" e interessantes.

\section{C) - A teCnOlOgia como UM AMBiente No QUAL ESTAMOS IMERSOS}

Em (apenas) dois casos, os depoimentos dos entrevistados apresentaram percepções da tecnologia como um ambiente cultural no qual a sociedade está imersa. Nessas falas, não estabelecemos a diferença entre a tecnologia e qualquer outro artefato cultural. A tecnologia configura-se como um elemento que faz parte do dia a dia, intervindo na relação com o mundo, isto é, a tecnologia não se constitui como ferramenta meramente instrumental, prática e utilitária. Nesse sentido, uma escola que verdadeiramente integre a tecnologia é um ambiente que não se coloca à parte da vida, não se distancia nem do mundo exterior, nem da realidade dos alunos, pois tudo - práticas, relações sociais, acesso à informação, construção de conhecimento, comunicação e aprendizagem - faz parte de uma mesma realidade, constituindo um ecossistema de sentidos partilhados.

Eu acho que a escola, assim como a mídia, ela é produtora de cultura, então as crianças estão inseridas na cultura aqui da escola, a mídia traz muita coisa para elas e não tem como a escola fugir do que a mídia traz, a gente quer entrar em uma cultura escolar em que as crianças ajam daquela forma como a gente acha que tem que ser, mas a gente não pode fugir daquilo que faz parte do dia a dia delas e a mídia hoje está muito presente. E eu acho que na escola a gente tem que ajudar as crianças a ter um olhar crítico sobre a mídia, pra elas se darem conta do que a mídia está dizendo para elas, e daquilo ali, o que elas podem aproveitar ou não, e que elas tenham consciência do que é que a mídia está dizendo e do que realmente é, para que elas passem a olhar o mundo com outros olhos, senão elas acabam olhando o mundo só com os olhos da mídia. Mas a gente tem que sempre relativizar, sempre problematizar, então as crianças trazem o tempo todo questões para nós, porque elas viram na internet, ou que elas estão vendo no celular, é um joguinho novo que apareceu. Eu uso bastante o data show na sala, então às vezes quando elas trazem alguma coisa nova, às vezes eu boto no data show, mostro. Quando eles falam de algum vídeo, alguma coisa, ou algum assunto novo, a gente vai lá no Google e pesquisa, mas a gente acaba usando no coletivo, por causa disso, porque aí é na minha sala, eu trago o meu computador, com a minha internet, aí vai funcionar, não tem erro. E eu acho que nosso papel é esse, de questionar, para que eles possam olhar. (Professora de Ensino Fundamental I, escola 05).

Eu acho que tem muito a ver com o mundo que a gente vive. As modificações que a gente sofreu no mundo estão meio que entrando nas modificações que a gente tem que fazer na escola. Eu acho que hoje em dia qualquer pessoa tem um celular na rua. Ninguém sai de casa sem um celular. Eu acho que essa mudança na sala de aula está começando a ser feita agora, meio que dando os primeiros passos. É... meio que já tivemos um avanço nisso, mas ainda é um tabu para alguns professores, algumas escolas, de um modo geral. Eu acredito. (Professor de matemática, escola 06).

Em suma, com relação à proposição assumida pela pesquisa de que a inserção das tecnologias no processo de ensino-aprendizagem implica uma superação da visão de tecnologia como ferramenta, e assumindo a necessidade de uma modificação cultural do fazer docente, podemos afirmar que a maioria dos professores entrevistados valoriza as tecnologias por suas múltiplas funcionalidades técnicas, mas poucos assumem a possibilidade de mudança do processo de ensino-aprendizagem a partir do seu uso.

A coleta de dados confirmou a necessidade de, no processo de formação de professores, destacarem-se debates e conscientização dos envolvidos no que diz respeito à importância da 
apropriação da tecnologia sob uma perspectiva mais cultural e menos funcional. Percebemos, portanto, a necessidade de valorização de espaços de questionamento mútuo entre professor e aluno, alimentando a reflexão crítica sobre o ensino e, ao mesmo tempo, buscando a conscientização dos agentes com atividades focadas nas etapas que envolvam a participação de professores e alunos no planejamento, no desenvolvimento e na avaliação das estratégias de mudança em relação ao conceito de inclusão digital e à integração das tecnologias na metodologia didática.

\section{CONSIDERAÇÕES FINAIS}

As reflexões de Postman e Weingartner (1978) sobre a crise da instituição escolar e a urgência de adaptação aos novos tempos mantêm a mesma atualidade de quando proferidas há décadas passadas. Como concluiu Norbert Wiener (1954), citado pelos autores, ao afirmar que "modificamos tão radicalmente o nosso meio ambiente que temos agora de modificarmo-nos também, a fim de existirmos nesse novo meio", urge, assim, historicamente, uma necessidade de mudança, que muitas vezes teima em não se concretizar, sobretudo no espaço educativo (POSTMAN; WEINGARTNER, 1978, p. 224).

A pesquisa apresentada evidencia como a percepção dos atores escolares reflete uma visão de tecnologia como apoio e suporte adicional à prática do professor sem, no entanto, questionar a necessidade de transformação da prática em si a partir da tecnologia. No geral, a pesquisa verificou que há consciência, entre os professores e gestores entrevistados, de que os fenômenos de mudança cultural em curso estão intimamente relacionados à presença das mídias na sociedade. As tecnologias são apresentadas pela maioria dos sujeitos participantes da pesquisa como um elemento disruptivo e, portanto, impossível de ser ignorado pela escola e seus processos educacionais. Entretanto, não se questionam os fundamentos das práticas de ensino-aprendizagem consolidadas, a organização escolar e disciplinar, as formas e os caminhos do aprender, da maneira como as tecnologias questionam a realidade. Isto é, de modo geral, os meios são considerados de forma utilitária, pelo que podem servir, e não entendidos como um ambiente imersivo, um filtro tangível da nossa forma de conhecer o mundo. Por conseguinte, emergem indicações de quais seriam os usos corretos ou incorretos das tecnologias como se, de fato, elas constituíssem ferramentas caracterizadas pela neutralidade.

Assim, a partir dos resultados obtidos, é possível concluir que existe a necessidade de percorrermos caminhos outros de formação docente que apontem para uma aprendizagem transformadora, capaz de envolver a mudança estrutural nas premissas básicas do pensamento, das crenças e das ações educacionais. Uma mudança de consciência que altere drástica e definitivamente o modo não somente de encarar as tecnologias em relação à educação, mas também de perceber a imersão no habitat da cultura digital.

Como bem ressaltam Postman e Weingartner (1978, p. 25), uma mudança em um meio nunca é linear, aditiva, apenas cumulativa. A introdução de uma nova tecnologia afeta todo o meio, ou seja, um novo elemento altera a totalidade do meio, ocasionando, consequentemente, um ambiente totalmente novo, o que pressupõe, portanto, a (co)existência de novos padrões, percepções, compreensões e estratégias de sobrevivência e adaptação. Diante disso, porque 
não anunciar, como os autores, a "necessidade de um novo tipo de Educação"? Uma Educação que aprenda com o passado, compreenda e desmistifique o presente e aponte para um futuro menos temeroso. Uma Educação que almeje a formação de alunos inquisitivos, flexíveis e criativos, capazes de enfrentar incertezas e crises da sociedade contemporânea (MOREIRA, 2000). Uma Educação que busque a motivação e os interesses reais dos alunos, não deixando que a presença de tecnologias na sala de aula substitua a mediação do professor. Uma Educação que forme alunos críticos e conscientes, que não precisem aprender o "uso correto" das tecnologias, podendo se orientar por valores mais fundamentais, consolidados na e pela escola. Uma Educação que não tenha medo das idas e vindas do caminho e que reconheça as ambivalências do percurso e a sabedoria do tempo.

\section{REFERÊNCIAS}

BUZATO, M. E. K. Cultura digital e apropriação ascendente: apontamentos para uma educação 2.0. Educação em Revista, Belo Horizonte, v.26 n.03 p. 283-304, dez. 2010.

CASSIANI, S. H. de B.; CALIRI, M. H. L.; PELÁ, N. T. R.. A teoria fundamentada nos dados como abordagem da pesquisa interpretativa. Revista Latino-América Enfermagem, vol. 4 n. 3, pp. 75-88, dezembro 1996.

CARVALHO, L. M.; BARICHELLO, E. M. da R. Legitimação das organizações midiáticas no ecossistema digital. In: RUBLESCKI, A.; BARICHELLO, E. M. da R. (Orgs). Ecologia da Mídia. Santa Maria: Facos, 2013.

DALUZ, L. B. “Redação, professora?! Ah não!!!": dialogando com as crianças em suas produções em sala de aula e na Internet. Niterói: Intertexto, 2014.

GLASER, B.; STRAUSS A. The Discovery of Grounded Theory. New York: Aldine, 1967.

HEINSFELD, B. D.; PISCHETOLA, M. Cultura digital e educação, uma leitura dos estudos culturais sobre os desafios da contemporaneidade. Revista Ibero-Americana de Estudos em Educação, vol. 12, n. esp. 2, agosto 2017.

LEMOS, A. Cibercultura como território recombinante. In: TRIVINHO, E.; CAZELOTO, E. (Orgs). A cibercultura e seu espelho: campo de conhecimento emergente e nova vivência humana na era da imersão interativa. São Paulo: ABCiber, Instituto Itaú Cultural, 2009.

LÉVY, P. As Tecnologias da Inteligência: o futuro do pensamento na era da informática. Rio de Janeiro: Editora 34, 1993.

LOGAN, R. Figure/Ground: Cracking the McLuhan Code. E-Compós, Brasília, v.14, n3, set/dez, 2011.

MACHADO, I. Ecologia das extensões culturais. Revista FAMECOS, Porto Alegre, $\mathrm{n}^{\circ}$ 39, agosto de 2009.

MALHEIROS, G. Tecnologias digitais e prática docente: contextos de apropriação e trajetórias possíveis. Dissertação de Mestrado, PPGE/PUC-Rio, 2017.

MCLUHAN, M. The Gutenberg Galaxy: the making of typographic man. Toronto: University Toronto Press, 1962.

MCLUHAN, M. Understanding Media: the extensions of man. New York: New American Library, 1964. 
MCLUHAN, M. Entrevista com Marshall McLuhan. Revista da Associação Nacional dos Programas de Pós-Graduação em Comunicação - E-compós, Brasília, v.14, n.3, set./dez. 2011.

MOREIRA, M. A. Aprendizagem significativa crítica. Atas do III Encontro Internacional sobre Aprendizagem Significativa, Lisboa, 11-15 setembro de 2000.

NAUMANN, L. A.; PISCHETOLA, M. Práticas de leitura e autoria na perspectiva dos multiletramentos: relato de pesquisa em escolas municipais do Rio de Janeiro. Nuances, v. 28, p. 127-146, 2017.

ONG, W. J. Orality and literacy: The technologizing of the word. London: Routledge, 1982.

ONG, W. J. Ecology and some of its future. Explorations in Media Ecology 1(1), pp. 5-11, 2002.

PISCHETOLA, M. Tecnologias em sala de aula: contribuições para uma pedagogia sustentável. $\mathbf{3 6}^{\mathbf{a}}$ reunião da Anped, Florianópolis (SC), 2015.

PISCHETOLA, M. Inclusão digital e educação: a nova cultura da sala de aula. Petrópolis: Vozes, 2016.

POSTMAN, N. The Reformed English Curriculum. In: EURICH, A. C. High School 1980: The Shape of the Future in American Secondary Education. New York: Pitman Pub. Corp, 1970.

POSTMAN, N. Tecnopólio. São Paulo: Nobel, 1994.

POSTMAN, N. Five Things We Need to Know About Technological Change. Conferência em Denver, Colorado, 27 de março de 1998. Disponível em: < http://web.cs.ucdavis.edu/ rogaway/classes/188/ materials/postman.pdf>

POSTMAN, N. The Humanism of Media Ecology. In: Proceedings of the Media Ecology Association. 2000. Disponível em: <http://www.media-ecology.org/publications/MEA_proceedings/ v1/postman01.pdf>

POSTMAN, N.; WEINGARTNER, C. Contestação - nova fórmula de ensino. Rio de Janeiro: Expressão e Cultura, 1978.

RUBLESCKI, A.; BARICHELLO, E. M. da R. (Orgs). Ecologia da Mídia. Santa Maria: Facos, 2013.

SCOLARI, C. Hipermediaciones: Elementos para una teoría de la comunicación digital interactiva, Barcelona: Gedisa, 2008.

SCOLARI, C. Ecología de los medios. Mapa de un nicho teórico. In: Quaderns del CAC, n 34, Vol. XIII (1), Jun./2010.

SCOLARI, C. Media Ecology: Exploring the Metaphor to Expand the Theory. In: Communication Theory. v. 22, Issue 2, p. 204-225, May 2012.

STRATE, L. A Media Ecology Review. Communication Research Trends, Vol. 23, N. 2, 2004.

VYGOSTKY, L. S. A formação social da mente. São Paulo: Martins Fontes Editora, 4ª Ed., 1991.

VYGOSTKY, L. S. A Construção do pensamento e da linguagem. São Paulo: Martins Fontes Editora, 2009.

WIENER, N. The Human Use of Human Beings. Boston: Houghton Mifflin, 1954. 
Artigo recebido em: 10/06/2018

Aprovado em: 20/07/2018

Contato para correspondência:

Magda Pischetola.

E-mail:magda@puc-rio.br.

1 A conferência em que Neil Postman apresentou esse novo conceito/campo de estudo foi o Annual meeting of the National Council of Teachers of English, cujas atas foram publicadas em 1970 com o título "The Reformed English Curriculum".

2 Palestra ministrada pelo autor no Kenyon College, Ohio, em 2005. Transcrição integral disponível no endereço: <http://bulletin.kenyon.edu/x4280.html>. Último acesso em: novembro de 2017.

3 Tradução nossa do original: "A medium is a technology within which a culture grows; that is to say, it gives form to a culture's politics, social organization, and habitual ways of thinking".

4 As falas dos sujeitos entrevistados são apresentadas sem modificações ou correções, respeitando-se a fala de cada um, os vocábulos utilizados e a ordem dos discursos, tais como foram pronunciados. 